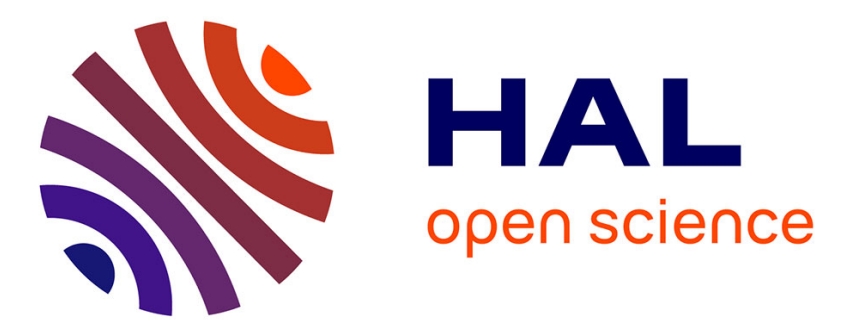

\title{
Estimating canal pool resonance with auto tune variation
}

\author{
A.J. Clemmens, X. Litrico, P.J. van Overloop, R. Strand
}

\section{To cite this version:}

A.J. Clemmens, X. Litrico, P.J. van Overloop, R. Strand. Estimating canal pool resonance with auto tune variation. Journal of Irrigation and Drainage Engineering-ASCE, 2012, 138 (9), p. 9 - p. 15. 10.1061/(ASCE)IR.1943-4774.0000384 . hal-00763800

\section{HAL Id: hal-00763800 \\ https://hal.science/hal-00763800}

Submitted on 11 Dec 2012

HAL is a multi-disciplinary open access archive for the deposit and dissemination of scientific research documents, whether they are published or not. The documents may come from teaching and research institutions in France or abroad, or from public or private research centers.
L'archive ouverte pluridisciplinaire HAL, est destinée au dépôt et à la diffusion de documents scientifiques de niveau recherche, publiés ou non, émanant des établissements d'enseignement et de recherche français ou étrangers, des laboratoires publics ou privés. 


\section{Estimating Canal Pool Resonance with Auto Tune Variation}

\section{A. J. Clemmens' ${ }^{1}$, Member, ASCE, X. Litrico ${ }^{2}$, P.-J. van Overloop ${ }^{3}$, R. J. Strand ${ }^{4}$}

Abstract: The Integrator-Delay (ID) model is commonly used to model canal pools which do not exhibit resonance behavior. Simple step tests are often used to estimate ID model parameters; namely, delay time and backwater surface area. These step tests change the canal inflow at the upstream end of the pool and observe water depth variations at the downstream end. Some knowledge of the canal pool characteristics are needed to determine the amount of flow change and its duration. The Auto Tune Variation (ATV) method is one method for determining the duration of these step tests. Pools that are under backwater over their entire length tend to exhibit oscillations duc to resonance waves. Pseudo-Binary-Random-Sequence (PBRS) tests have been used to determine the resonance fiequency of such pools, where step tests with different durations are used. PBRS tests are difficult to implement in practice and may not provide the resonance frequency. The intent of this paper is to demonstrate on a real canal that the ATV method can determine both the resonance frequency and the resonance peak height for canal pools whose water levels oscillate.

\section{Introduction}

Automatic control of canals requires a process model relating water flows and levels from which a controller can be designed. Schurmans ef al. (1999a) developed a simple linear model of canal pool response; the Integrator-Delay (ID) model. The model assumes that the canal pool las two

\footnotetext{
' Center Director, U.S, Arid Land Agticultural Research Center, 21881 N. Cardon Lane, Maricopa, AZ 85138 Bert.clcmmęr@ars.usda.gov

${ }^{2}$ Researcher, Cemagref, UMR G-Eau, 361 rue J.F. Brenton, B.P. 5095, 34196 Montpelier Cedex 5, France Xavicr.litrico@cemagref.fr

${ }^{3}$ Researcher, Delf Univ. of Technology, Scction IVater Managenent, Stevimweg 1, 2628CN, Delft, The Netherlands p.j.vanoverloop@citg.tudiclf..sl

${ }^{4}$ Blectrical Engineer, U.S. Arid Land Agricultural Research Center, 21881 N. Cardon Lane, Maricopa, AZ 85138 bob.strand@ats.usth.gov
} 
parts. The downstream end of the pool acts as a reservoir (Integrator) and the water level responds to changes in inflow and outflow based on its water surface area, $A$. The upstream end of the pool is assumed to be at normal depth, where upstream flow changes gradually arrive downstream. This part of the pool is characterized by a delay time, $\tau$. Schummans et al. (1999b) show that the ID model fits canal response to changes in flow under two conditions; 1 ) The changes are relatively simall, and 2) The fiequency of the input is below the resonance frequency, ${ }^{(1)_{R}}$, implying very gradual clianges. Pools that have a significant portion of their length under normal depth typically do not exhibit resonance. But pools that ate entirely under backwater usually do not have a delay $(\tau=0)$. Other pools can be a combination of these two responses.

Clemmens and Schummans (2004) used Linear-Quadratic Regulator (LQR) methods to develop) multi-pool canal controllers, based on an ID process model. Generally, the ID model parameters ( $A$ and $\tau$ ) werc detcrmincel fiom simple step tests, wherc the upstream inflow was changed suddenly. These controllers have been applied to control both simulation (ASCE test canal 1, Arizona Canal) and real canals (WM canal) where canal pools are not under backwater (Clemmens and Wahlin 2004, Bautista et al, 2006, Clemmens and Strand 2010). Litrico et al (2007) used the auto tune variation (ATV) method to determine ID model parameters for the Giguac Canal. Once the ID model parameters were determined from ATV, they used gain and phase margin specifications developed by Litrico and Fromion (2006) to design simple Proportional Integral Differential (PID) or PI controllers, which were then applied successfully to the canal.

Control of canal pools whose water levels oscillate has proven more challenging. Schuurmans (1997) proposed simple procedures for design of proportional-integral controllers for individual canal pools that are under backwater. Low-pass filtering was used to account for the resonance. This procedure requires knowledge of both the resonance frequency and the resonance peak height. Litrico and Fromion (2004) propose an Integrator Delay Zero (IDZ) model, where the zero takes the resonance behavior into account. Unfortunately, the $1 \mathrm{DZ}$ model as presented does not capture the resonance peak height. Silvis et al. (1998) applied system identification to determine ID model parameters. Overloop et al. (2010) used system identification tools to 
identify canal pool propertics, including the resonance frequency and peak height, $M_{R}$. They superimposed a Random Binary Signal (RBS) (step inputs) in upstrcam disclarge of roughly $\pm 0.08 \mathrm{~m}^{3} / \mathrm{s}$ ( $5 \%$ of capacity), and frecpuencies that ranged from $60 \%$ to $120 \%$ of the resonance frequency estimated from wave celerity. They showed that the resonance fiequency was close to that expected from wave celcrity. The resonance-pcak height was also accurately predicted. However, the backwater surface area was not well predicted. They recommended simpler methods to obtain the low-frequency properties (i.e., backwater sufface area). A drawback of system identification using PRBS is that the resonance frequency needs to be estimated beforchand. For certain type of canal pools, e.g. with culvert in the pool or with irregular crosssections, this may be difficult. Another issue is that the tests take a long time to execute (e.g. morc than 8 hrs). In this period, the downstream flow rate needs to be kept constant. Over such a long period, drif of the water level, which is supposed to remain close to target level (sctpoint), is unavoidable. Hence, application of system identification signals to a real canal is difficult and not likely to be routincly adopted.

ATV is a more manageable way of generating a disturbance signal. The ATV method was applicd to the same canal pool as Overloop et al. (2010). In this paper, the results of the ATV method in dctcrmining the resonance frequency and resonance-peak height are presented, and the potential for ATV as a general proccdure for identifying all canal pool propertics is discussed.

\section{Canal Resonance}

For an infinitely long canal with constant flow ratc, bottom slope, canal cross section and frictional resistance, the water depth will eventually reach a uniform value with distance, so called normal clepth. The valuc of normal depth changes with discharge such that the energy loss from frictional resistance matches the bottom slope. A change in upstream discharge causes a wave to travel downstream. The initial (dynamic) wave travels at the speed of celerity, $c$ (discussed below). However, this wave travels too fast for the inflow to create the new steadystatc water depth. After a long time, the speed of the wave is based on continuity (kinematic 
wave) or going from one steady statc to another. In most real canals, the wave speed is somewhere between the kinematic and dynamic wave speeds (Bautista et al. 2003, Municr ef al., 2010). Under normal depth conditions, the dynamic wave is damped relativcly quickly because of hydraulic resistance. Obstructions to flow (e.g., canal structures) cause the water depth to be deeper, such that friction is reduced. When the water depth is at normal depth, the depth of a wave caused by a disturbance is generally small, such that resonance belavior is usually not significant. Howcver, as the depth is increascd above normal depth, the magnitude of the depth and the wave speed both increase. For canal pools that combine a length where water is at normal depth with a length where water is under backwater, waves in the backwater part are clamped when they intersect the nomal depth portion, such that resonance behavior is usually not significant. However, for pools that are entirely under backwater or that are relatively short, waves will reflect off both upstream and downstream structures. Deeper depths allow waves to propagate more casily. Lower flow rates can result in a larger backwater part, so resonance behavior would be greater (e.g., assuming same downstrcam water level). Overloop (2006) gives a description of the effects that different canal parameters, and their variation, have on the resonance peak height.

For canal pools under backwater, water travel at the speed of celerity, $c$, where

$$
c=\sqrt{g D}
$$

where $g$ is the acceleration of gravity and $D$ is the hydraulic depth (cross sectional area divided by fop width). The wave travel speed is $c+v$ going downstream, where $v$ is the average flow velocity, and c-v going upstream. The wave travel time, $T_{r}$, is thus

$$
T_{r}=T_{r b}+T_{r u}=\frac{L}{c+v}+\frac{L}{c-v}
$$

where $L$ is the pool length, $T_{r D}$ is the time for the wave to travel to the downstream end, and $T_{r} U$ is the time for the wave to travel to the upstream end.

Figure 1 shows the downstream water level deviation (simulation results from Sobek, 2000) for a step change in upstream discharge in a pool wherc the upstream portion is under normal depth. Note that the water level initially increases very slowly and then gradually increases at a steady 
rate. The initial increase represents the time for the dynamic wave to arrive. The dashed line is the ID model fit. The slope of the ID model line is the flow change divided by the backwater surface area, $A$. The time delay, $\tau$, is the time from the upstream flow change to the time where the ID model line crosses zero ( 7 minutes in Fig. 1). As the depth increases, the backwater surface area also increases and the slope of the water level deviation decreases. The pool demonstrated in Figure 1 is pool CD-12 of the Central Arizona Irrigation and Drainage District (CAIDD). The pool has a bottom width of $1.219 \mathrm{~m}$, side slopes 1.5:1 (horizontal to vertical), slope $0.0012 \mathrm{~m} / \mathrm{m}$, length $922 \mathrm{~m}$, a downstrcam set point depth of $1.539 \mathrm{~m}$, and a capacity of $3.115 \mathrm{~m}^{3} / \mathrm{s}$. The flow change was $0.156 \mathrm{~m}^{3} / \mathrm{s}$, and the backwater surface area was approximately $1400 \mathrm{~m}^{2}$.

Figure 2 shows the Bode plots for this pool. The Bode plot was determined by linearizing the full Saint-Venant equations around the steady state solution and assuming a Manning friction coefficient of 0.016 . The Bode plot magnitude for a pure integrator (with or without a delay), such as the ID model, would be a straight line with a slope of -20 decibels (dB). Note that the magnitude is nearly linear at this slope. However, the line bends horizontal at high frequencies representing the Zero as described by the IDZ-model proposed by Litrico and Fromion (2004). This zero should not cause concern for control because the magnitude is low, structure position changes are slow, and low-pass filtering, commonly used to dampen sensor noise, is sufficient to remove the high frequency response.

Figure 3 shows the downstream water level deviation for a step change in upstream discharge in a pool which is entirely under backwater (simulation results from Sobek, 2000). Note that the initial increase is rather rapid, followed by oscillations, before rising at a more or less constant rate. The dashed line is the ID model response. Note that when this ID model is projected back to zero depth change, the time matches the time of the upstream flow change, or $\tau=0$. Canal pool details (NB-12) are given in the example below. For Figure 3, the flow change was $0.016 \mathrm{~m}^{3} / \mathrm{s}$ and the backwater surface area was approximately $2950 \mathrm{~m}^{2}$. 
Figure 4 shows the Bode plots for this pool with resonance. Resonance peaks can be clearly seen in Figure 4. Note that in canal pools, typically, the first resonance peak has a phase lag of $-180^{\circ}$ and is therefore prone to violating the gain margin stability criterion. Knowledge of the frequency and magnitude of this first resonance peak, next to the storage area and delay time, is sufficient for filter and controller design. If a controller is designed at the resonance frequency, the response at higher frequencies is not a significant concern because they are above the cut-off frequency of the closed loop system.

\section{Auto Tune Variation Method}

The Auto Tune Variation (ATV) method is a classical automatic tuning method that has been applied to many industrial processes (Hang et al 2002). Its purpose is to determine the ultimate gain and ultimate period, typically for design of PI or PID controllers. The ATV method uses a relay feedback that applics step changes in inflow, positive and negative, around a steady state. The size of the step change should be based on allowable deviations from set point. Too large a step change might overtop the canal. Too small of a step change might be lost in signal noise. The timing of the step changes is based on the downstream water level response. The procedure is as follows. Steady state is manually established in the canal at, or at least close to, the water level setpoint. A change in upstream inflow is made (positive or negative). When the downstream water level starts to change, the change in inflow is reversed. Each time the downstream water level crosses the setpoint, the change in inflow is reversed. The canal therefore oscillates around the steady-state, in a limit cycle at a frequency corresponding to a phase lag of exactly $180^{\circ}$ between the input and the output signals. In this test, the limit cycle was well established after 5 oscillations.

For canal pools where the upstream length is under normal depth, Litrico et al. (2004) demonstrated that the ATV procedure would provide good estimates for both the delay time and backwater surface area. They show that the magnitude of the ultimate frequency can be determined from 


$$
M_{R}\left(\omega_{R}\right)=\frac{\pi \Delta y}{4 \Delta Q}
$$

where $\Delta y$ is the change in water depth and $\Delta Q$ is the change in flow ratc. The $\pi / 4$ term is needed because there are step changes in flow rate and approximately sinusoidal changes in water depth.

For canal pools under backwater, the ATV procedure would only be useful if the changes in upstream flow match the resonance frequency. The time from a flow change upstream to the downstream water level change corresponds to the time for the wave to travel downstream, $T_{r D}$. If a positive wave is sent downstream and reflects back upstream, adding another positive wave at that moment should provide the maximum effect on the water level. In this case, the input signal of the upstream gate is in counterphase with the output signal of the downstream measurement location, so the input and output signals are $-180^{\circ}$ out of phase. This study was conducted because it was uncertain whether or not the timing would be sufficiently accurate in a real application. If this is the case, then the changes in observed water depth would provide the resonance-peak height directly, i.e. the point in the Bode-diagram of the first resonance peak (see Figure 4).

Determining the resonance frequency and resonance peak height is not sufficient, by itself, to fully characterize the canal's response. In addition, the gain at lower frequencies is required. Adding a delay in the loop during the ATV test is suggested in the literature as a method to estimate the response at frequencies other than the ultimate frequency (Hang et al., 2002). For a pure integrator, the integrator gain (inverse of the backwater surface area) can be found from (Litrico et al. 2007)

$$
A=\frac{1}{\omega_{L} \cdot M\left(\omega_{L}\right)}
$$

where $\omega_{L}$ is the frequency of the delayed ATV test. This equation is not appropriate for conditions near the resonance frequency. But this equation can be used if the frequency is sufficiently low. 
Test Canal

Simulations and a field test were executed on the NB lateral canal at the Central Arizona Irrigation and Drainage District. The NB-12 pool was selected because it has significant resonance response, it does not have culverts or other obstructions in the pool, and because it had bcen previously investigated by Overloop et al (2010). The pool is $793 \mathrm{~m}$ long, has a slope of 0.0002 , bottom width $0.61 \mathrm{~m}$, side slope of 1.5 (horizontal to vertical). The downstream gate is $0.76 \mathrm{~m}$ wide and $1.14 \mathrm{~m}$ high. In-line weirs next to the gate at $1.14 \mathrm{~m}$ depth allow water to continue downstream if the gate is closed. The capacity is $1.56 \mathrm{~m}^{3} / \mathrm{s}$. The nominal depth setpoint at the downstream end of the pool is $1.08 \mathrm{~m}$, although a lower water depth of $0.957 \mathrm{~m}$ was chosen for this test to avoid over topping the weirs during high discharge tests. (This reduced the backwater surface area determined in Figure 2). Field tests were conducted on May 6, 2010. The steady state flow rate was $0.322 \mathrm{~m}^{3} / \mathrm{s}$ and the flow change was $\pm 0.17 \mathrm{~m}^{3} / \mathrm{s}\left(\Delta Q=0.34 \mathrm{~m}^{3} / \mathrm{s}\right)$.

The water depth just upstream from gate NB-12 (Downstream end of the pool) was measured with a pressure transducer. A temporary transducer was installed in the upstream end of the pool, just downstream from the upstream gate (NB-11A). The initial depth at the upstream end of the pool was $0.820 \mathrm{~m}$, giving an average depth in the pool of $0.889 \mathrm{~m}$. This gives a cross sectional area of $1.725 \mathrm{~m}^{2}$, a top width of $3.275 \mathrm{~m}$, a hydraulic depth of $0.527 \mathrm{~m}$, an average velocity of $0.19 \mathrm{~m} / \mathrm{s}$, and celerity speed from Eq (1) is $2.27 \mathrm{~m} / \mathrm{s}$. The estimated resonance time from Eq (2) is $703 \mathrm{~s}, \omega_{\mathrm{R}}=0.0089$. From Eq (2), the time for the wave to travel downstream, $T_{r D}$, is $322 \mathrm{~s}$ and the time for the wave to travel upstream, $T_{r U}$, is $381 \mathrm{~s}$. Thus change in the upstream depth were expected to lag behind changes in the downstream depth. Based on the average top width of flow, the backwater surface area should be approximately $2598 \mathrm{~m}^{2}(3.275 \mathrm{~m} * 793 \mathrm{~m})$.

Data from the pressure transducers were read by remote terminal units at the site and transmitted to the Supervisory Control and Data Acquisition (SCADA) system through spread-spectrum radios. The SCADA system was set up to display values of water depth deviation from setpoint, in this case the, initial water depth. The operator could remotely change gate position by specifying a flow set point for each gate. A flow controller adjusted the gate position to obtain 
the correct flow rate. Details of the SCADA system and associated controls are given in Clemmens and Strand (2010). The water depth observations were made every 10 seconds, while the flow control adjustments were made every 30 seconds.

As part of the field experiment, a delay term was added to the ATV test, in an attempt to determine the backwater surface area (system integrator). A 6 minute delay was chosen assuming that at low frequencies the system behaves as an integrator. An integrator has $90^{\circ}$ phase lag, so an extra $90^{\circ}$ needs to be put in the loop at a frequency where the ATV necds to start cycling. A pure delay gives a phase lag of $90^{\circ}$ at $\omega=\pi /\left(2 \tau_{\mathrm{d}}\right)$, so the delay time was calculated as $(\pi / 2) /\left(\omega_{R} / 2\right)$ which is approximately 6 minutes, thus essentially doubling the cycle time. In hind sight, a longer delay would have been more useful in order to make the closed loop system oscillate at a frequency that was further away from the resonance frequency.

Results of ATV with Simulation

Before ATV was implemented on the real canal, the response was simulated with unsteady flow simulation (Sobek, 2000). The results shown here are for a Manning roughness coefficient of $n=$ 0.016. Figure 5 shows the inflow to NB-12 based on the ATV rules from simulation with the unsteady-flow simulation software, Sobek (2000). Figure 6 shows the simulated water depths over time. The frequency found from the simulation for the standard ATV test (no delay) is $\omega_{R}=0.0087 \mathrm{rad} / \mathrm{s}$ (cycle time $=2 \pi / \omega_{\mathrm{R}}=720 \mathrm{~s}$ ). The magnitude $M_{R}$ from Eq. 3 is $0.234 \mathrm{~s} / \mathrm{m}^{2}$.

For the simulated ATV test, Figure 5 and 6 show the results of adding 6 - and 12-min delays. The oscillation period increases as the delay increases. The amplitude also changes, but not monotonically. This is clearly visible on the corresponding Bode plots which are depicted in Figure 7. The magnitude plot is the same, but the phase differs, depending on the value of the added delay. The standard ATV test makes the system oscillate at the first resonance frequency, while adding a delay of 6 minutes moves the oscillating frequency to about $0.0043 \mathrm{rad} / \mathrm{s}$ (1465 s). The change in water depth is roughly $0.068 \mathrm{~m}$, and from Eq $3, M_{R}=0.157 \mathrm{~s} / \mathrm{m}^{2}$. Finally, with 
an added delay of 12 minutes, the oscillating frequency is equal to $0.0018 \mathrm{rad} / \mathrm{s}$. Here $\Delta y=0.146$ and $M_{R}=0.337 \mathrm{~s} / \mathrm{m}^{2}$.

\section{Results of ATV from Ficld Experiment}

Figure 8 shows the inflow to pool NB-12 resulting from the ATV procedure. The resulting resonance period is $760 \mathrm{~s}$ (based on cycle of flow set point changes), so $\omega_{\mathrm{R}}=0.0083 \mathrm{rad} / \mathrm{s}$. Figure 9 shows the water depths recorded during the test. The first 70 minutes are the 5 cycles of the ATV test for determining the resonance. From casual observation, the upstream water depths are 180 degrees out of phase with the downstream depth, which implies that it is at the resonance frequency. However, the cycles of the upstream wave are on average about 35 seconds ahead of the downstream wave, based on the time to cross the steady state water depth. Since gate flow changes are made only every 30 second, the operator could not make changes exactly when the ATV criteria were met. Also, these changes were made manually. Finally, we expect the upstream depth to lag behind the downstream depth because of the difference in upstream versus downstream wave speed. The change in water depth between cycles (average for the last three cycles) is $0.100 \mathrm{~m}$. From Eq (3), the magnitude $M_{R}$ is $0.231 \mathrm{~s} / \mathrm{m}^{2}$, or $M_{R}=-12.7 \mathrm{~dB}$.

In the second part of the measurements, 6 minutes of delay time was added in order to make the closed loop oscillate at a lower frequency. The observed cycle time was $2190 \mathrm{~s}$, so $\omega_{\mathrm{R}}=0.0029$ $\mathrm{rad} / \mathrm{s}$. The water depth deviation, $\Delta y$, was $0.115 \mathrm{~m}$, which from Eq. 3 gives $M_{R}=0.265$, or $M_{R}=-$ $11.5 \mathrm{~dB}$.

Figure 9 also shows a comparison between the observed and simulated water level, when the measured upstream flow (Figure 8) was used as input to the simulation model, rather than using the ATV criteria (as in Figure 6). The Manning roughness coefficient was varied to get a good match between predicted and observed water-level responses. This value of Manning $n(0.016)$ is reasonable since the canal had recently been cleaned. For higher roughness values, the variation 
in water levels was significantly reduced (i.e., lower gain), while lower values of Manning $n$, resulted in a higher gains.

The water level at the upstream end of the pool (NB-11A in Figure 9) was measured with a temporary pressure transducer whose elevation was not accurately calibrated. Unfortunately, it was removed before a more detailed calibration could be done. In open-channels with canal pools under backwater, the upstream water surface clevation is influenced by the downstream water surface clevation. Water depth actually has a relatively minor effect. When the Manning roughness coefficient was adjusted to match the observed downstream water level response, the upstream water level was roughly $4 \mathrm{~cm}$ high. This could have been caused by an error in the bottom elevation at the upstream end of the canal relative to the downstream end of the canal or an error in the transducer elevation. This offset was applied to the results shown in Figure 9, which shows reasonably good prediction of water-level response. This amount of error is plausible. Fortunately, this error in upstream depth has no influence on the analysis presented here.

\section{System Identification}

In the ATV-tests exccuted on the model and real canal, the system was excited at frequencies that are of interest. Therefore, the input signal was expected to be useful for system identification, resulting in models that are accurate around the frequencies whose corresponding magnitudes can be used to compute the pool properties. Standard system identification tools (Mathwork 2003) were used to identify low order (Box-Jenkins) models for both the simulationmodel response and the field test. The procedure we apply is described in Overloop et al. (2010). Figure 10 and 11 gives the Bode plots of the model test and the field test respectively. Analysis of the residuals showed that both models were validated. The only required change from the procedure described in Overloop et al. (2010) is that a $7^{\text {th }}$ order model was used instead of a $5^{\text {th }}$ order model to accurately capture the first resonance peak (and to get the models validated). 
The values for the first resonance model found from the identified model using the model test data are: $\omega_{\mathrm{R}}=0.0084 \mathrm{rad} / \mathrm{s}$ and $M_{R}=0.238 \mathrm{~s} / \mathrm{m}^{2}$. These values essentially match the values found from the ATV-procedure applied to the model test. The values for the field test are $\omega_{R}=0.0086$ $\mathrm{rad} / \mathrm{s}$ and $M_{R}=0.261$. Here, the frequency is accurately estimated, while the magnitude is roughly $10 \%$ off.

With the results from system identification, conditions can be estimated at low frequencies. With the results for $\omega_{\mathrm{R}}=0.001 \mathrm{rad} / \mathrm{s}$, Eq. 4 provides estimates of $A$ for the model test and the field test of $2676 \mathrm{~m}^{2}$ and $3081 \mathrm{~m}^{2}$, respectively. The first one is remarkably close to the one estimated from the pool dimensions ( $3 \%$ ), while the value resulting from the field test is more than $15 \%$ off. Clearly this is the result of insufficient low frequency information in the identification signals as available from the field test.

\section{Discussion}

Table 1 presents the estimates for all pool properties resulting from the various tests and estimation methods. The largest errors likely resulted from inexact application of the ATV method in the field. The operator was not able to change the upstream flow quickly (or accurately) enough to hit the resonance frequency exactly. It is interesting that system identification was able to find a better estimate. Regarding the resonance peak height, it can be seen in Figure 5 that, when switching, the flow shows significant overshoot, 6 out of 9 times. Our actual test did not accurately produce a square wave output, as required for use of Eq. 3. System identification was able to account for this error and provide a better estimate.

The delayed ATV tests for the field $(0.0029 \mathrm{rad} / \mathrm{s})$ and simulation $(0.0043 \mathrm{rad} / \mathrm{s})$ tests resulted in very different frequencies, even though the same rules were used. When making a disturbance at other than the resonance frequency, there are multiple overlapping waves. Minor errors in our ability to model the primary wave can result in very different responses when observing the wave overlap. The wave overlap can be seen in Figure 12 by the sudden changes in downstream 
water depth at around $0.95 \mathrm{~m}$. Clcarly, the effect of these waves is different for the increasing and decreasing flows. It is significant that this response occurs close to the depth at which the ATV criteria cause the flow to cycle. Take for example the rise in water level at roughly 12:10 in Figure 9. Here, the field results and simulated results differ just when the depth crosses the initial water level. Thus while the overall response is similar, the ATV delay time might be quite different because of this difference in wave overlap. For our ficld test, the system was clearly not steady when switched from the standard to the delayed ATV test. Residual wave action during this test could have easily caused the cycle to be longer for this test.

The low frequency response, and thus the backwater surface area $\mathrm{A}$, can be determined from a simple step test, as demonstrated in Figure 3, or from the gain of a binary signal at a very low frequency. This is easy to do with simulation, but establishing a sufficiently steady condition for these tests in the field can be difficult. The ATV test has the advantage that it is not sensitive to the lack of a good steady condition. And as shown by our field test, the ATV test provided good parameter estimates even when conditions were far from steady and the resulting frequency was far from that expected.

Future research will continue to explore whether or not the ATV method can become a general procedure for determining canal pool properties, regardless of conditions within the pool. The method was previously shown to be applicable for canal pools that did not display significant resonance. Both the delay time and the backwater surface area could be determined. By applying the ATV procedure both with and without an extra delay, it was able to determine the resonance frequency and the resonance peak height with reasonable accuracy, and the backwater surface area approximately. If both a standard and delayed ATV test are run, it should be easy to determine whether resonance occurs since both should give the same backwater surface area if resonance does not exist (i.e., from Eq 4).

For canal pools with internal structures, particularly culverts, both resonance and a delay can exist. While this has not been tested, the procedure is expected to work here as well. If this is the 
case, then perhaps this one methodology can identify canal pool propertics regardless of their configuration.

\section{Conclusions}

The ATV method was applied in real time to a canal pool that exhibited resonance. The standard ATV approach was able to determine the resonance peak height and the resonance frequency. By adding a delay in the ATV response, an estimate for the backwater surfacc area, which serves as an integrator, was obtained. The delayed ATV approach is recommended for field use because it is not sensitive to steady conditions. The combination of a standard and delayed ATV test is proposed as a general method for determining canal pool properties for any canal configuration.

\section{References}

Bautista, E. and Clemmens, A. J. 2005. Volume compensation method for routing irrigation canal demand changes. Journal of Irrigation and Drainage Engineering 131(6), 494-503.

Bautista, E., Clemmens, A. J., and Strand, R. J. 2006. Salt River Project canal automation pilot project: simulation tests. Journal of Irrigation and Drainage Enginecring 132(2), 143-152.

Bautista, E., Strelkoff, T. S., and Clemmens, A. J. 2003. General characteristics of solutions to the open-channel flow feedforward control problem. Journal of Irrigation and Drainage Engineering 129(2):129-137.

Clemmens, A. J. and Schuurmans, J.. 2004. Simple optimal downstream feedback canal controllers: Theory. Journal of Irrigation and Drainage Engineering. 130(1), 26-34. 
Clemmens, A.J. and Strand, R.J.. 2010. Downstream-water-level control test results on the WM lateral canal. Journal of Irrigation and Drainage Engineering. 136(7), 460-469.

Clemmens, A. J. and Wahlin, B. T. 2004. Simple optimal downstream feedback canal controllers: ASCE test case results. Journal of Irrigation and Drainage Engineering 130(1), 3546.

Hang, C., Astrom, K, and Wang, Q. 2002. Relay feedback auto-tuning of process controllers-A tutorial revicw. J. Process Control, 12, 143-162.

Litrico, X., Malaterre, P.-O., Baume, J.-P., Vion, P.-Y., and Ribot-Bruno, J. 2007. Automatic tuning of PI controllers for an irrigation canal pool. Journal of Irrigation and Drainage Engineering, 133(1), 27-37.

Litrico, X., Fromion, V. (2004). "Simplified modeling of irrigation canals for controller design," Journal of Irrigation and Drainage Engineering, 130(5), 373-383.

Litrico, X. and Fromion, V. (2006). Tuning of robust distant downstream PI controllers for an irrigation canal pool. I: Theory. Journal of Irrigation and Drainage Engineering, 132(4), 359-368.

Munier, S., Belaud, G. and Litrico, X. (2010), A closed-form analytic expression for the response time of an irrigation canal, Journal of Irrigation and Drainage Engineering, 136(10), 677-684.

Overloop,P.J. van (2006), 'Model Predictive Control on open water systems', Ph.D.-dissertation Delft University of Technology, The Netherlands.

Overloop, P.-J. van, Miltenberg, I.J., Bombois, X. Clemmens, A.J., Strand, R.J., Giesen, N.C. van de. Hut, R. 2010. Identification of resonance waves in open water channels. Control Engineering Practice. 
MathWorks 2003 Matlab User Guide. The MathWorks, Inc., Natick, Massachusetts.

Schuurmans, J. 1997. Control of water levels in open channels. Ph.D.-dissertation Delft University of Technology, The Netherlands.

Schuurmans, J., Hof, A., Dijkstra, S., Bosgra, O.H., and Brouwer, R. (1999a) Simple water level controller for irrigation and drainage canals. Journal of Irrigation and Drainage Engineering, 125(4), 189-195

Schuurmans, J., A. J. Clemmens, S. Dijkstra, R. H. Ahmed, O. H. Bosgra, and R. Brouwer. 1999b. Modeling of irrigation and drainage canals for controller design. Journal of Irrigation and Drainage Engineering 125(6), 338-344.

Sobek 2000 Manual and Technical Reference. WL|Delft Hydraulics, Delft, The Netherlands.

Silvis, L. G., Hof, A., van den Hof, P. M. J., and Clemmens, A. J. 1998. System identification on open-channels. p. 219-224. In Hydroinformatics '98 Proc. of the Third International Conference on Hydroinformatics, Copenhagen, Denmark, 24-26 Aug. 1998, A. A. Balkema, Rotterdam, The Netherlands. Babovic \& Larsen (ed.) 
Figure 1. Water level deviation response to a step change in upstream inflow for pool CD-12 at $30 \%$ capacity.

Figure 2. Bode plots for pool CD-12.

Figure 3. Water level deviation response to a step change in inflow for pool NB-12 at $10 \%$ of capacity.

Figure 4. Bode plots for pool NB-12 (10\% of flow capacity and Mannings=0.016).

Figure 5. Flow rates for simulated ATV test results for canal pool NB-12 with 0,6 and 10 minute delays.

Figure 6. Water depths for simulated ATV test results for canal pool NB-12 with 0, 6 and 10 minute delays.

Figure 7. Bode plots of NB-12 canal pool with different added delays.

Figure 8. Inflow to pool NB-12 for ATV test (May 6, 2010).

Figure 9. Observed and predicted water depths for ATV test on pool NB-12 (May 6, 2010). (NB-11A is upstream depth. NB-12 is downstream depth).

Figure 10. Bode plots of identified model using model data

Figure 11. Bode plots of identified model using field test data. 
「able 1

jick here to download Table: Table 1 IRENG6084.doc

Table 1. Estimation results from field and simulation tests for canal pool NB-12.

\begin{tabular}{|c|c|c|c|c|c|}
\hline & \multirow[b]{2}{*}{$\begin{array}{l}\text { From pool } \\
\text { dimensions }\end{array}$} & \multicolumn{2}{|l|}{ Field Data } & \multicolumn{2}{|c|}{ Simulation Data } \\
\hline & & $\begin{array}{l}\text { Data and } \\
\text { Eq. } 3\end{array}$ & $\begin{array}{l}\text { System } \\
\text { Identification }\end{array}$ & $\begin{array}{l}\text { Data and } \\
\text { Eq. } 3\end{array}$ & $\begin{array}{l}\text { System } \\
\text { Identification }\end{array}$ \\
\hline Storage area $A\left(\mathrm{~m}^{2}\right)$ & 2598 & & 3081 & & 2676 \\
\hline $\begin{array}{l}\text { Resonance } \\
\text { Frequency } \omega_{\mathrm{R}}(\mathrm{rad} / \mathrm{s})\end{array}$ & 0.0089 & 0.0083 & 0.0086 & 0.0087 & 0.0084 \\
\hline $\begin{array}{l}\text { Resonance peak } M_{R} \\
\left(\mathrm{~s} / \mathrm{m}^{2}\right)\end{array}$ & & 0.231 & 0.261 & 0.234 & 0.238 \\
\hline
\end{tabular}

¿ัర

㟧

近

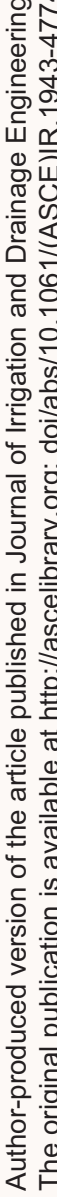



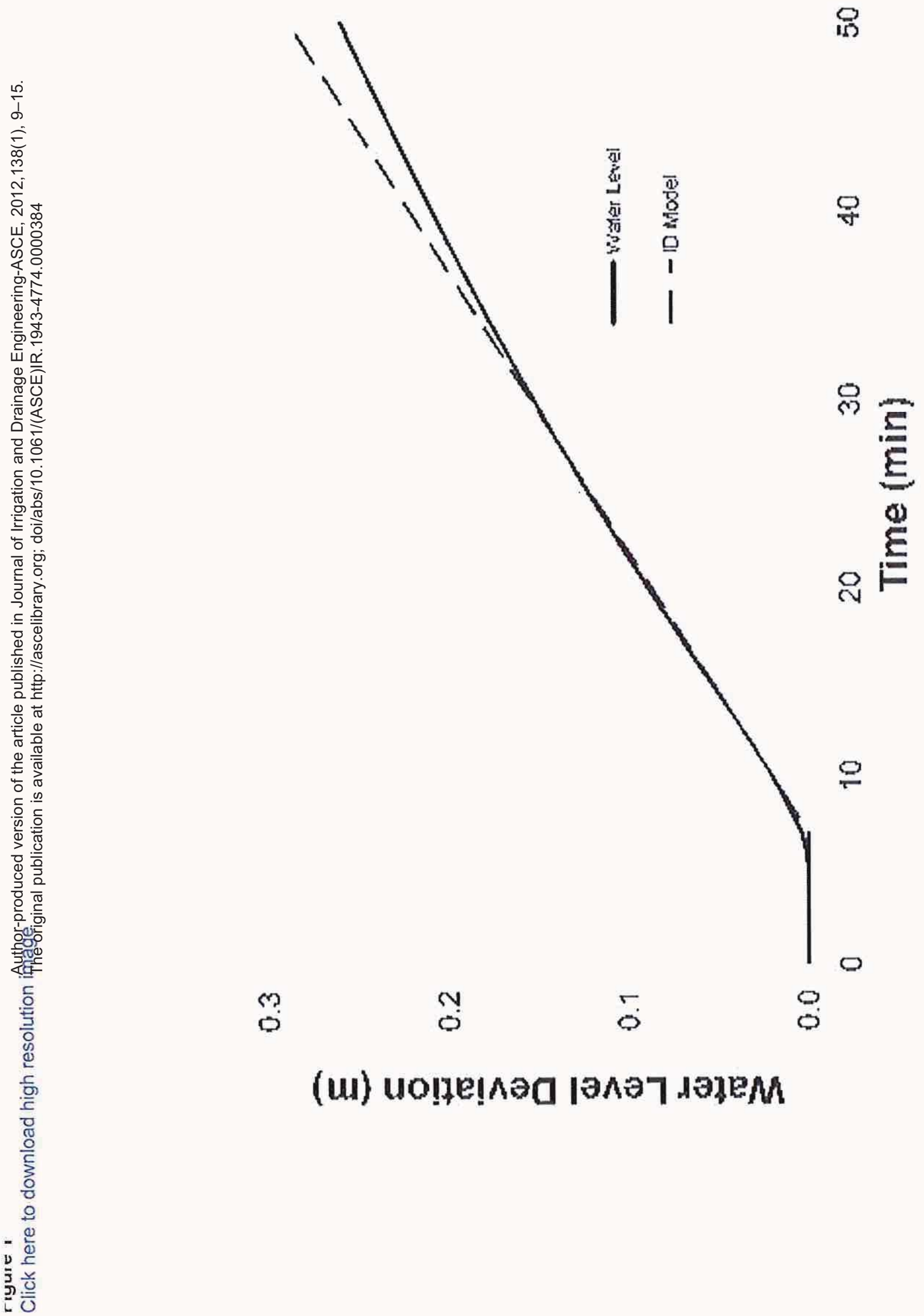


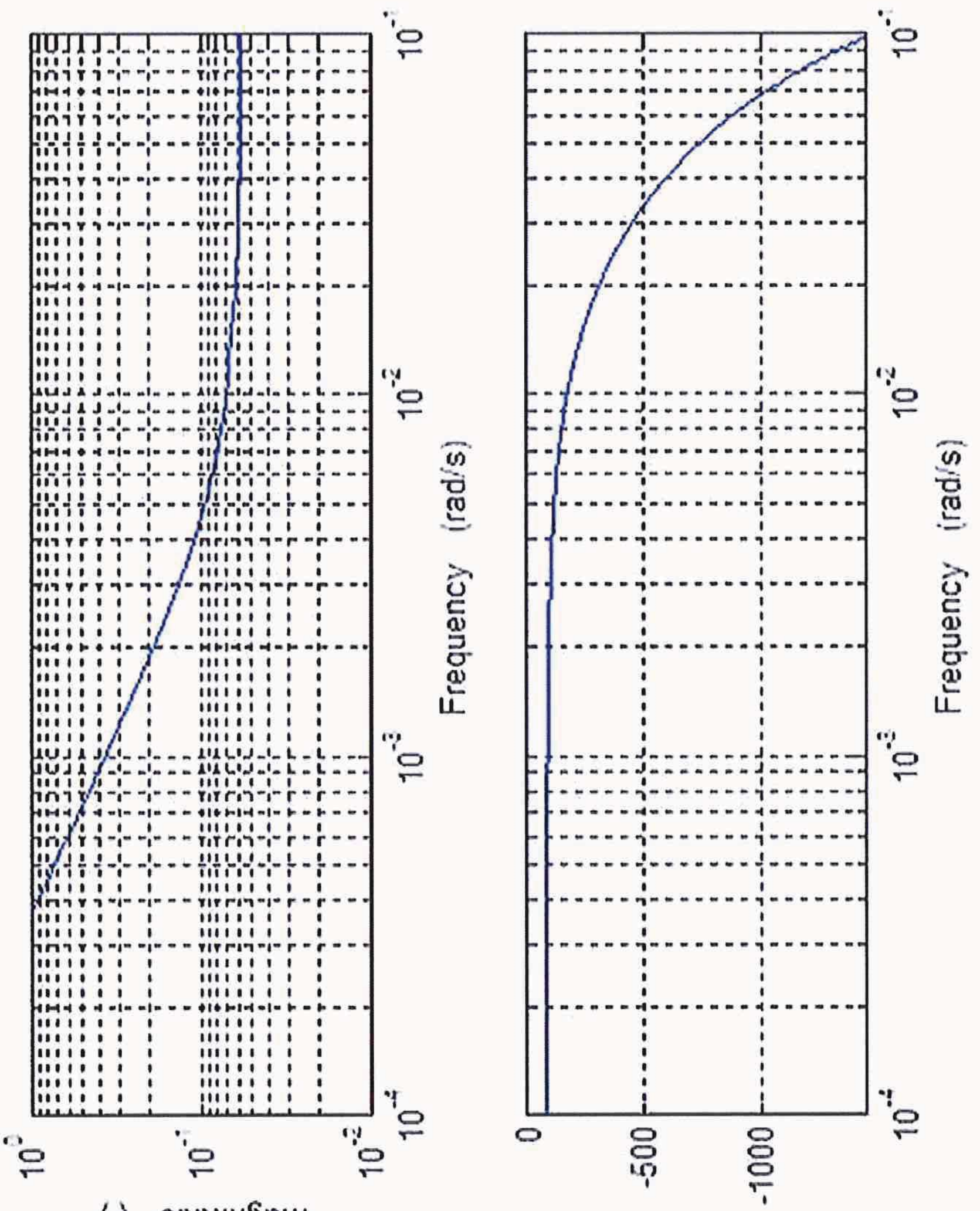

(-) apm!nuбen

(6ap) aseyd 
ถ
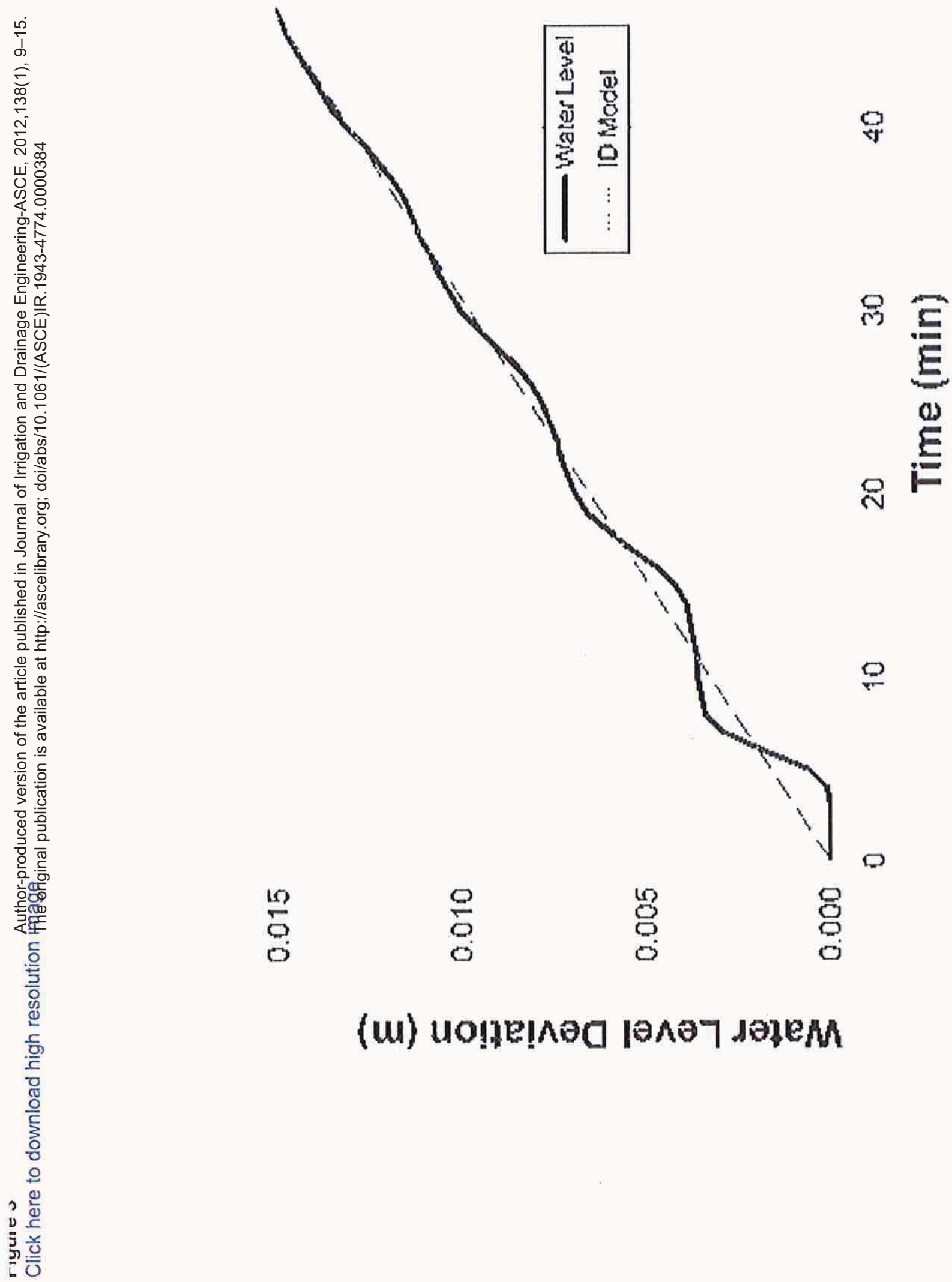

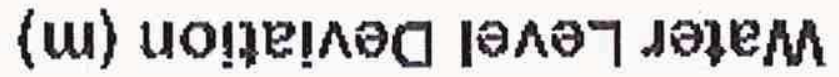




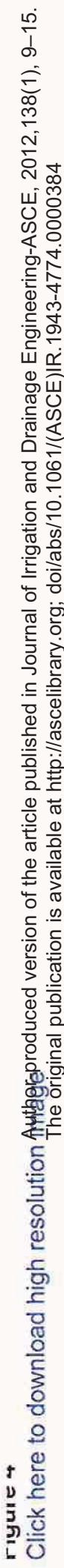

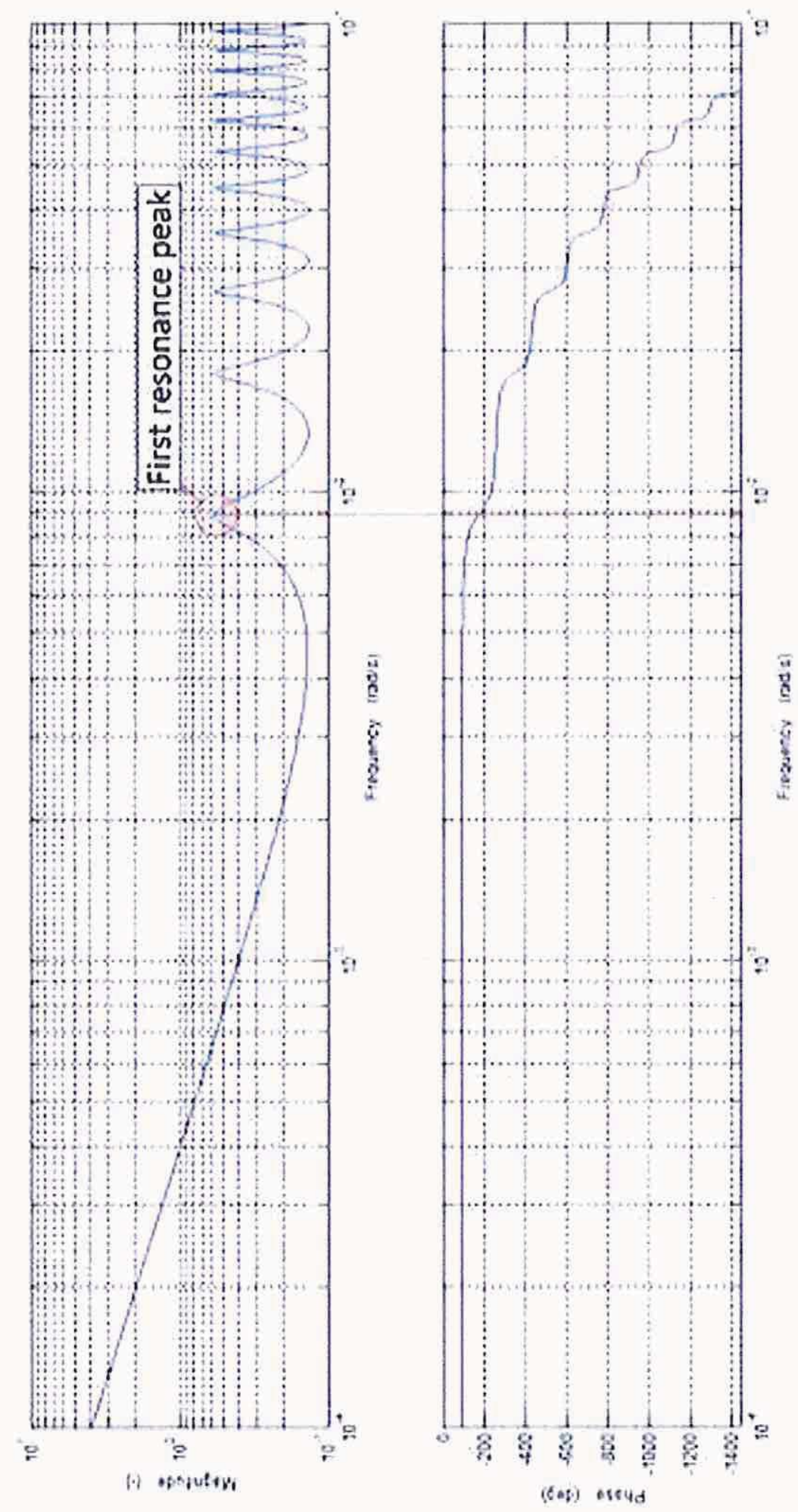


$$
=-------
$$$$
\text { :- - - - - - }
$$$$
-----1-7
$$

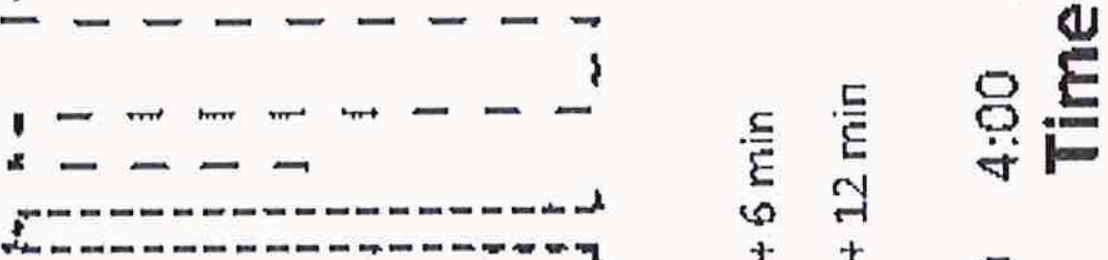

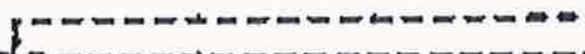

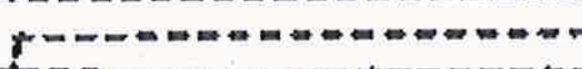

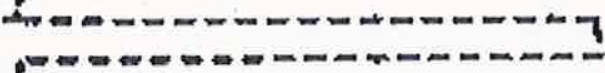

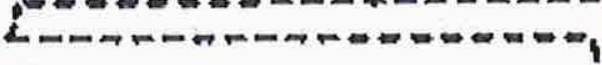

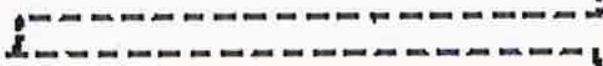
है हो है

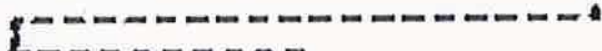

$$
\ddot{\infty}
$$
4 


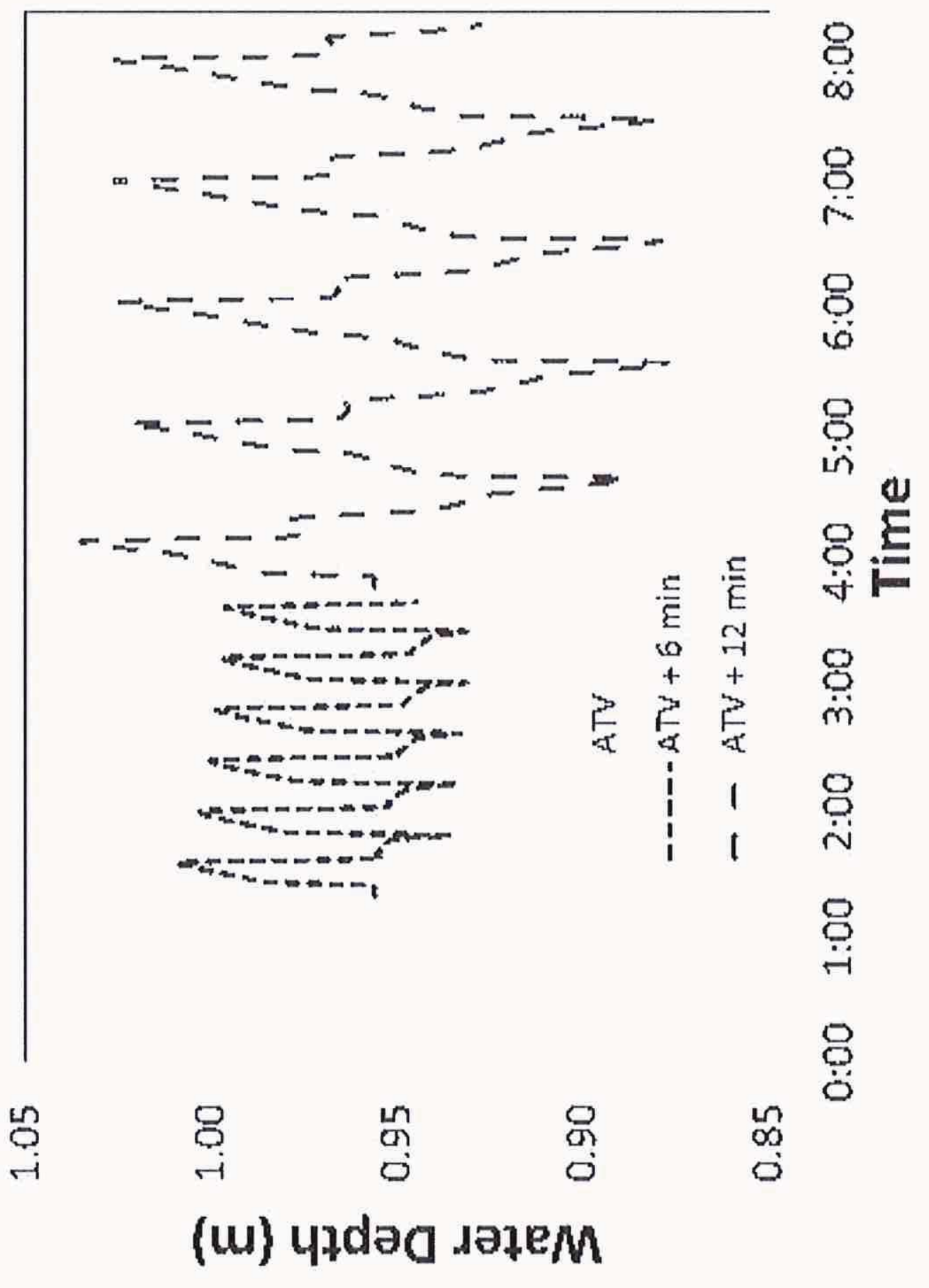

†NM 


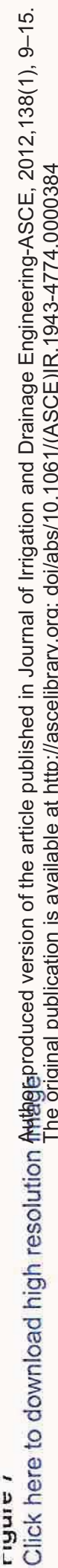
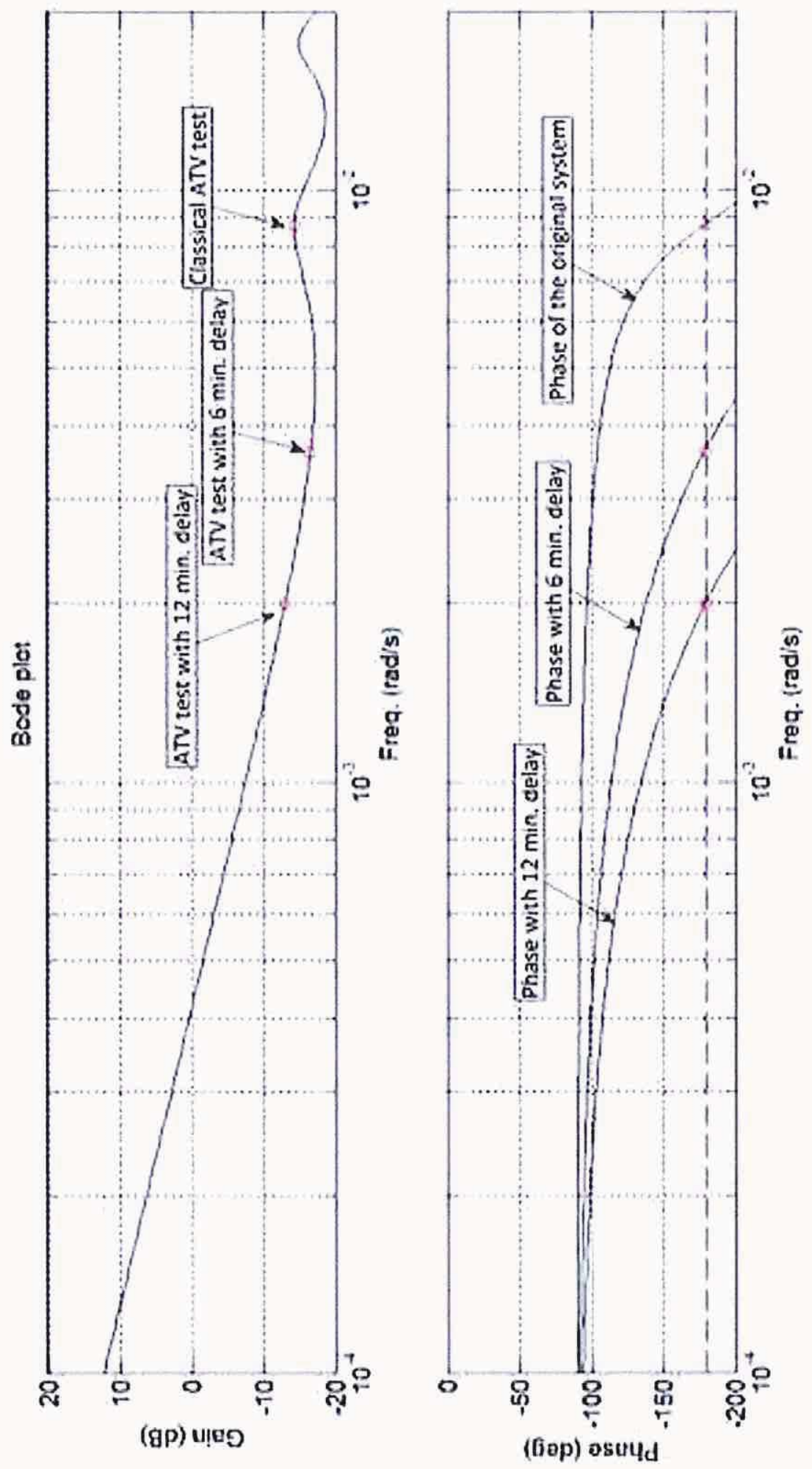

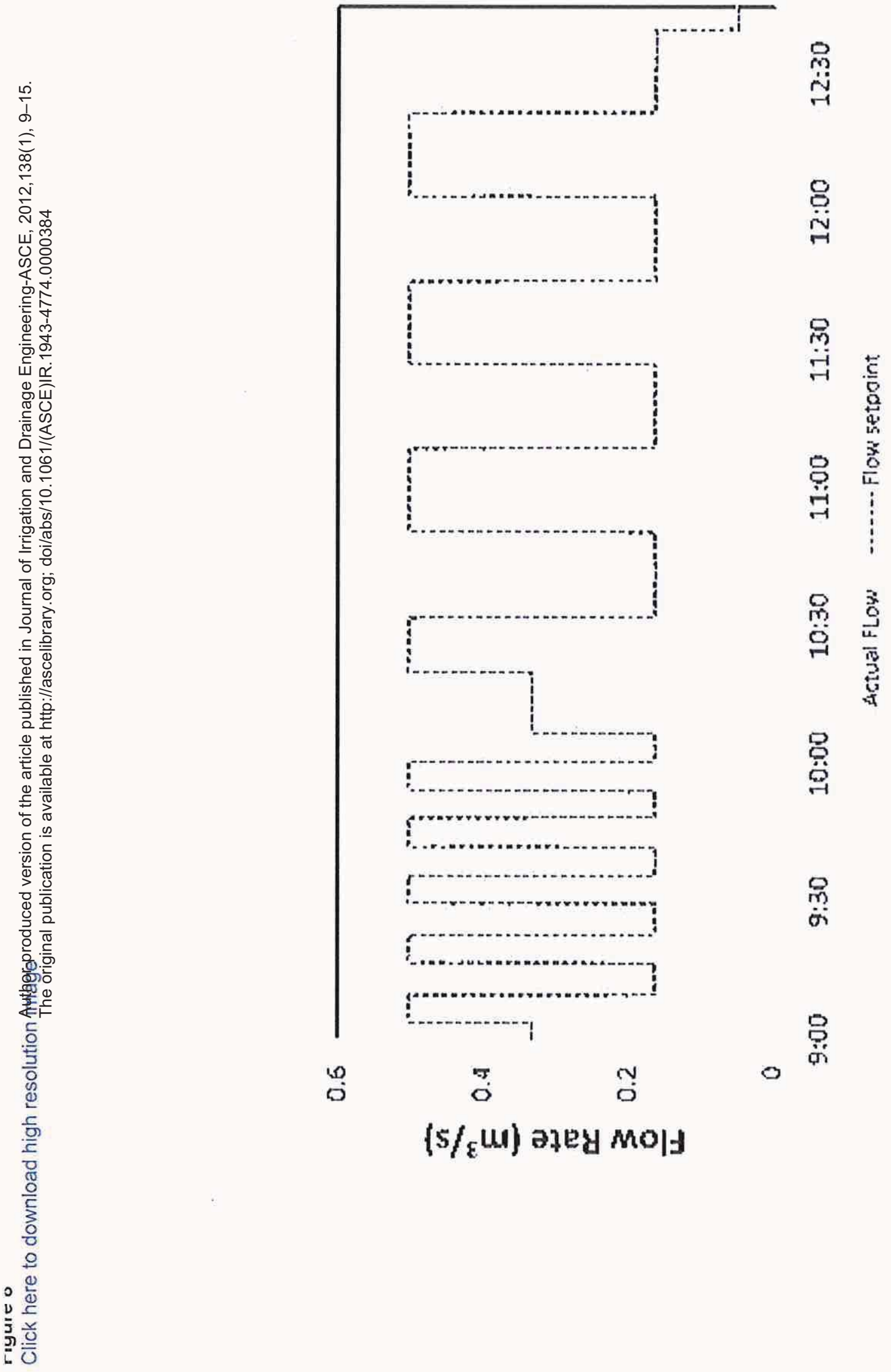


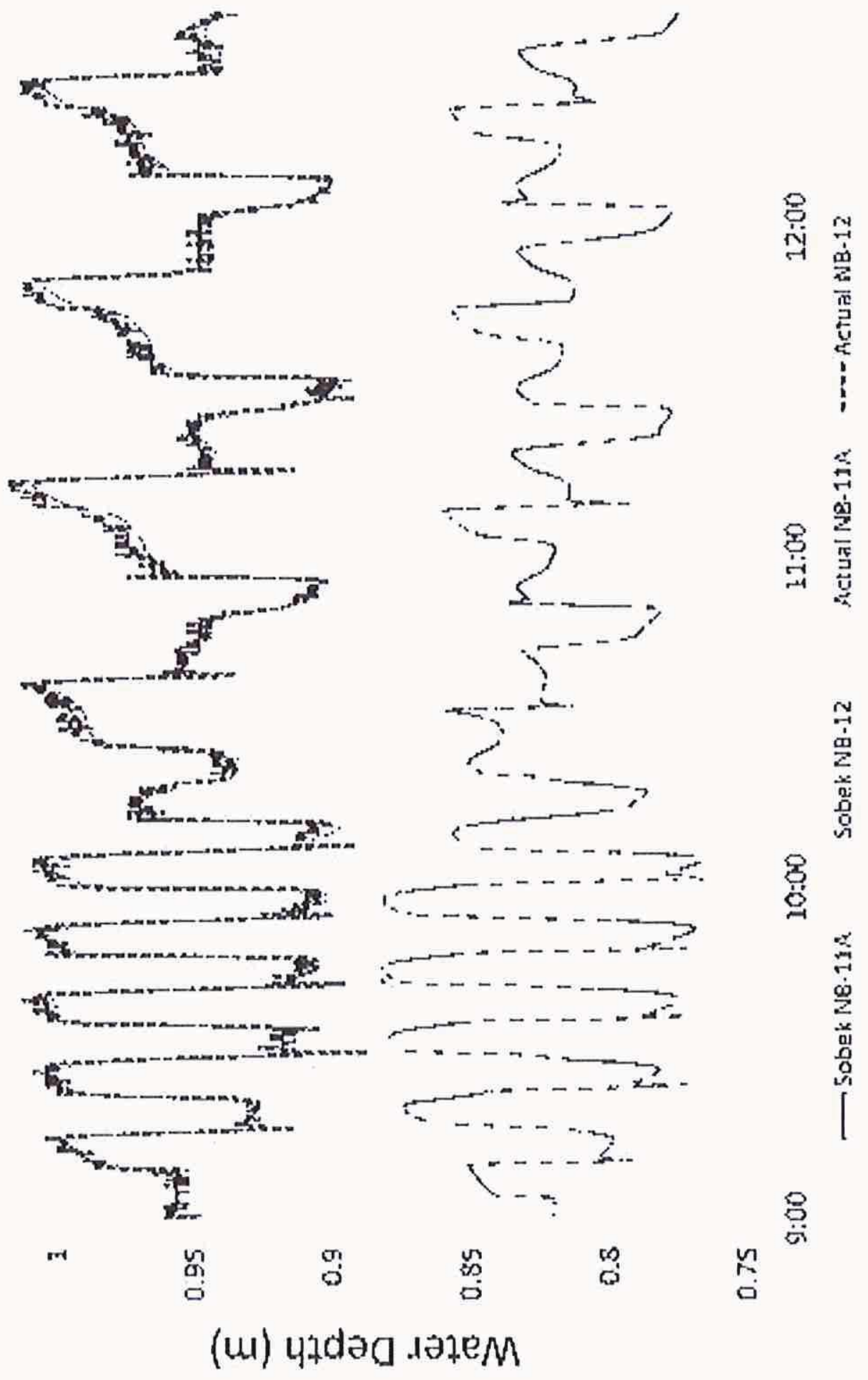




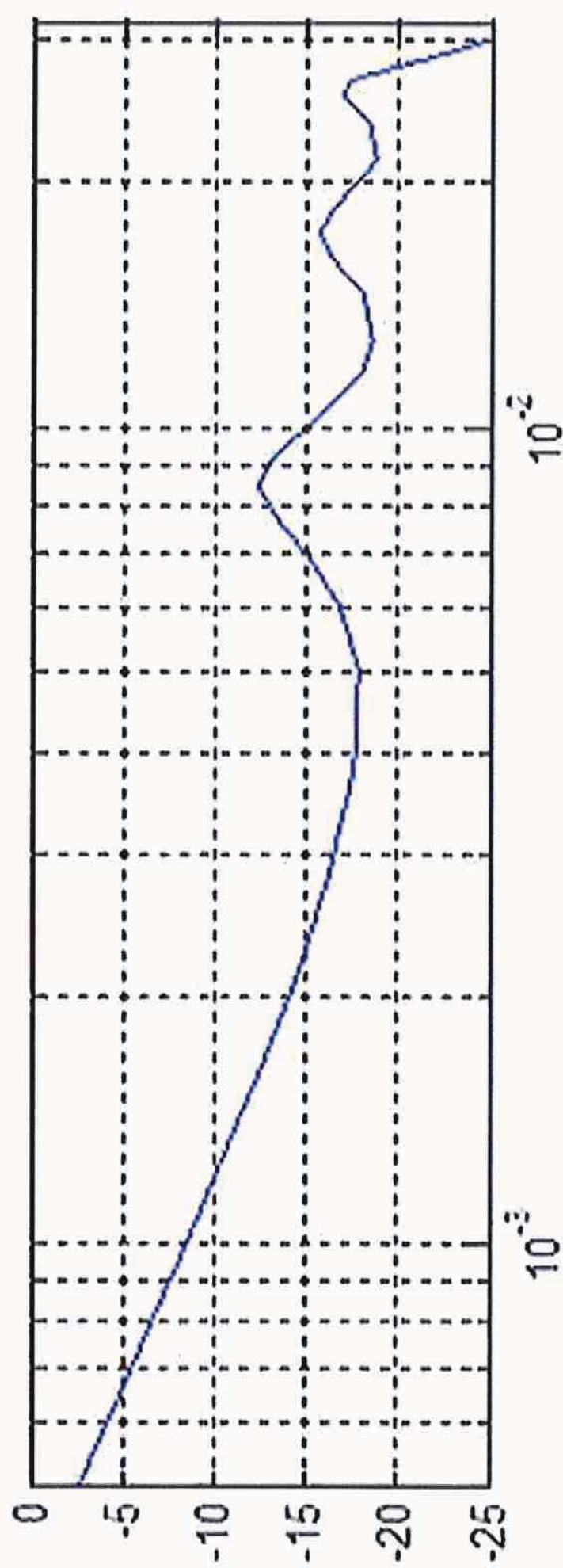

(घp) apm!!ubew

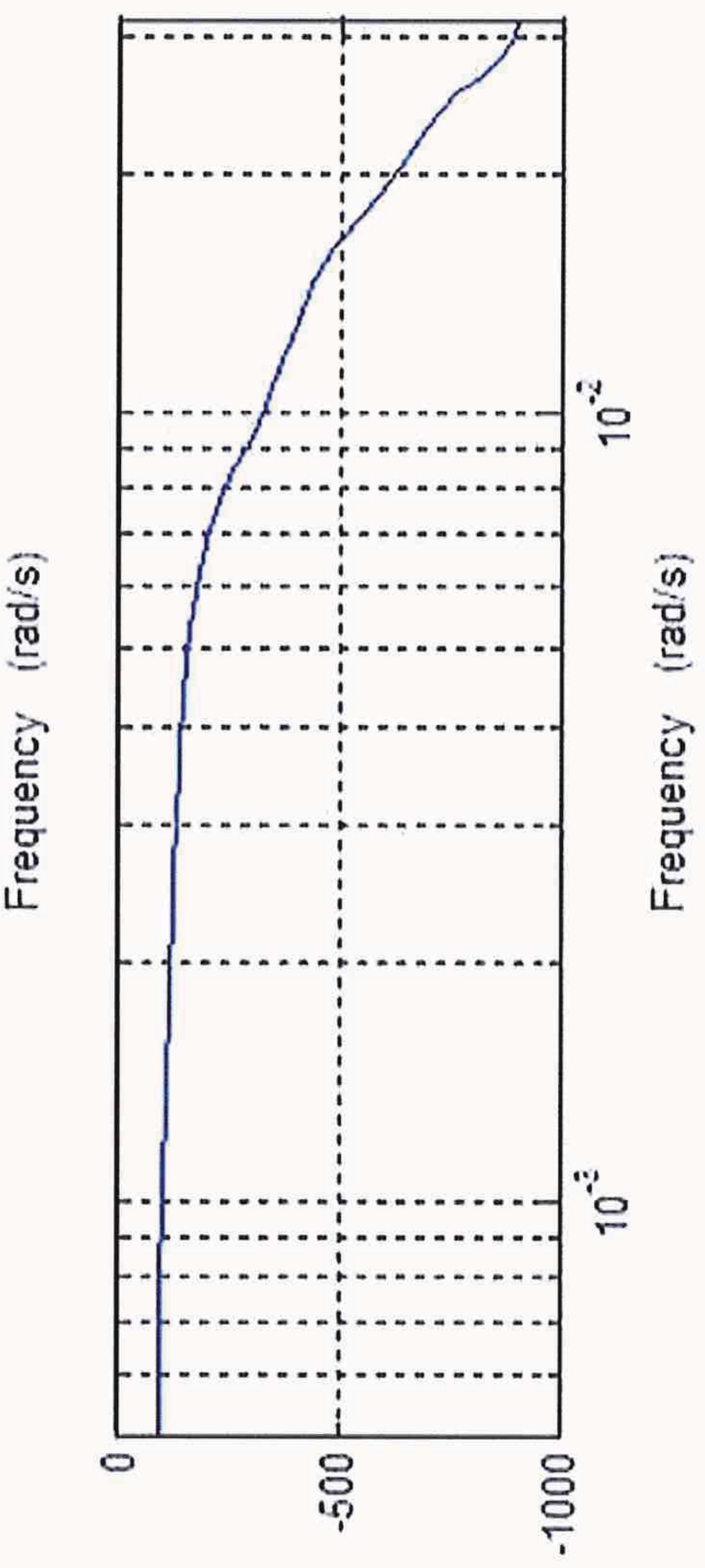

(Бар) aseyd 


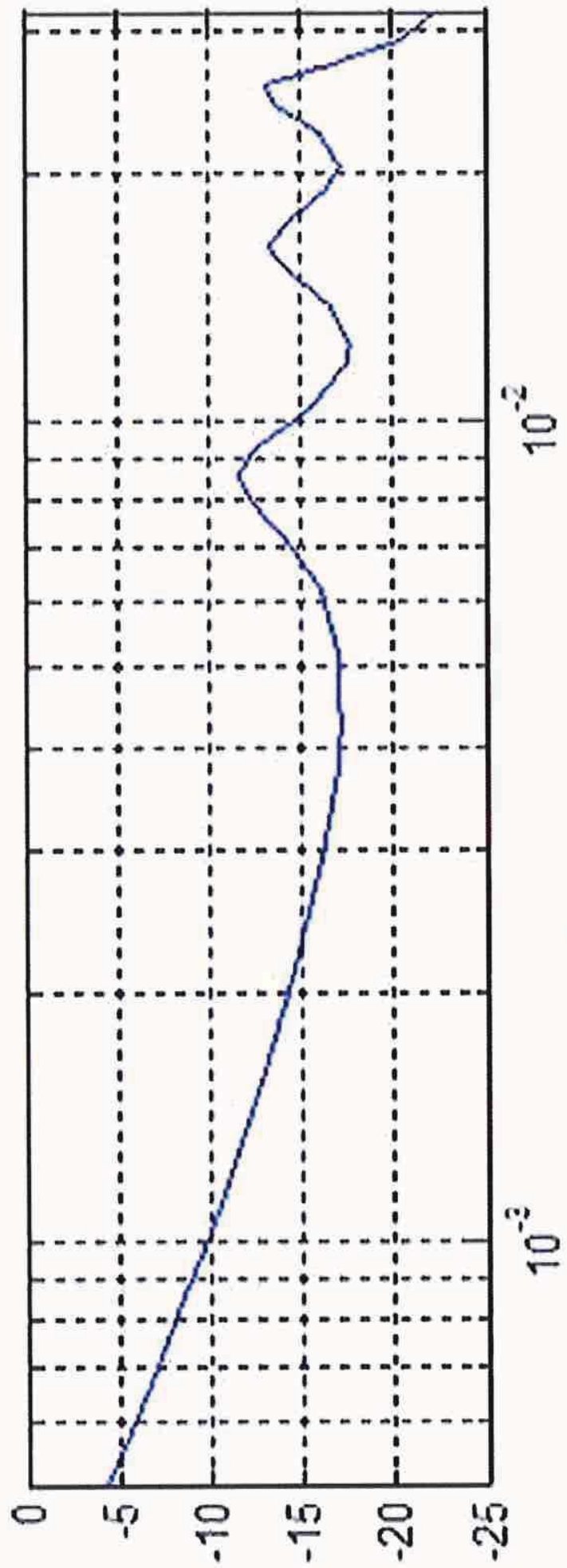

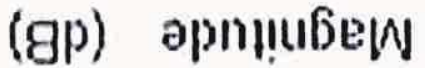

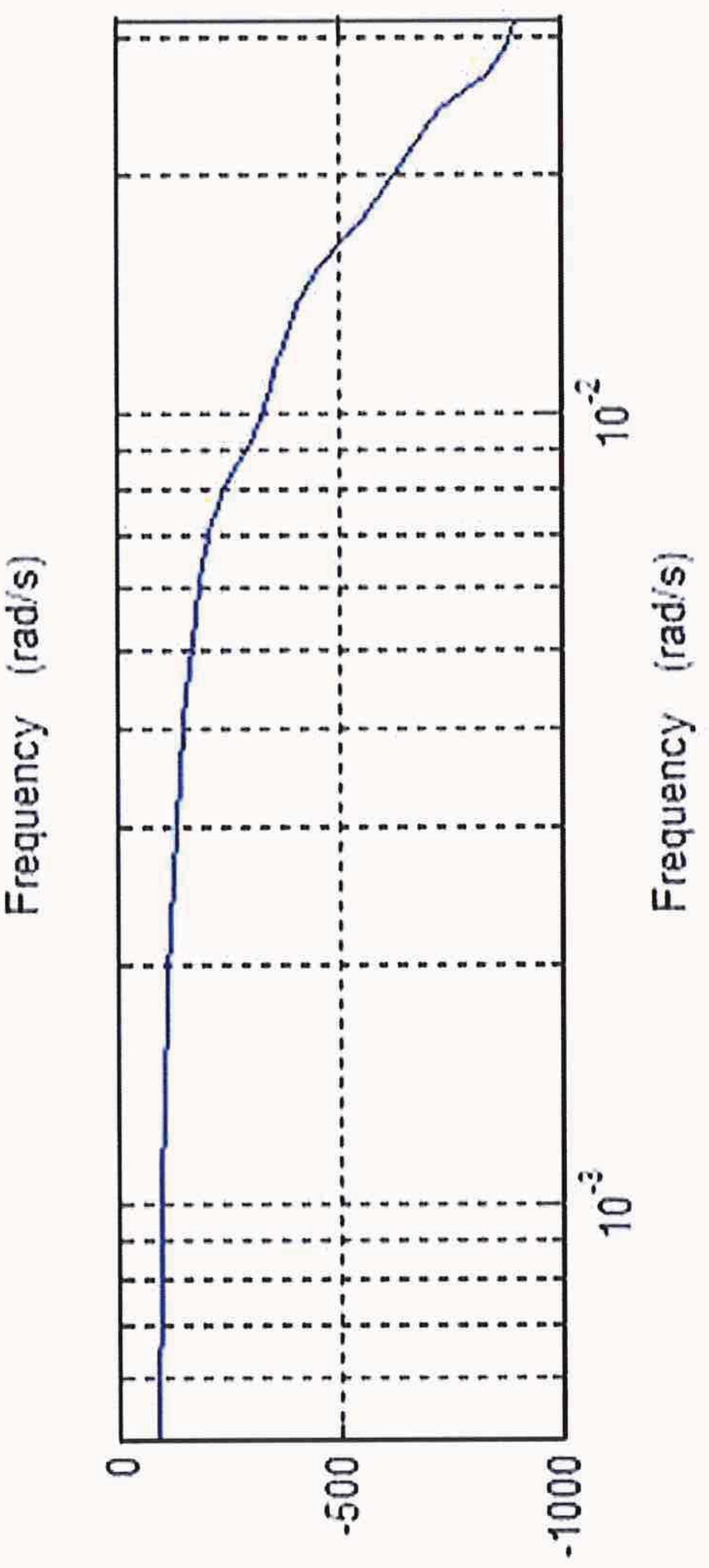

(6ap) aseyd 